\title{
DSGE Models and the Lucas Critique. A Historical Appraisal.
}

\section{Francesco Sergi}

University of the West of England (UWE), Bristol 


\title{
DSGE Models and the Lucas Critique. A Historical Appraisal
}

\author{
Francesco Sergi*
}

\begin{abstract}
This contribution to the history of the economic thought aims at describing how "Econometric Policy Evaluation: A Critique" (Lucas, 1976) has been interpreted through four decades of debates. This historical appraisal clarifies how Lucas's argument is currently understood and discussed within the dynamic stochastic general equilibrium (DSGE) approach.

The article illustrates how two opposite interpretations of the Lucas Critique arose in the early 1980s. On the one hand, a "theoretical interpretation" has been championed by the real business cycle (RBC) approach; on the other hand, an "empirical interpretation" has been advocated by Keynesians. Both interpretations can be understood as addressing a common question: Do microfoundations imply parameters' stability? Following the RBC theoretical interpretation, microfoundations do imply stability; conversely, for Keynesians, parameters' stability (or instability) should be supported by econometric evidence rather than theoretical considerations.

Furthermore, the article argues that the DSGE approach represent a fragile compromise between these two opposite interpretations of Lucas (1976). This is especially true for the recent literature criticizing the DSGE models for being vulnerable to the Lucas Critique.
\end{abstract}

Keywords: DSGE models, Lucas Critique, microfoundations

JEL codes: B22

\footnotetext{
*University of the West of England Bristol. francesco.sergi@uwe.ac.uk.
} 


\section{Introduction}

According to a standard narrative on the history of macroeconomics, "Econometric Policy Evaluation: A Critique" (Lucas, 1976) had two consequences 1 Firstly, it provided an ultimate criticism of the macroeconometric models à la Klein and Goldberger (1955). As Robert Hall puts it, this macroeconometric approach - which was dominant in the 1960s - has been "devastated by the theoretical and empirical force of the [Lucas] critique" (Hall, 1996, 38) ${ }^{2}$ Secondly, Lucas (1976) sets in motion a new research program for macroeconometric modeling. In The Rational Expectations Revolution, Preston Miller claims for instance that "the Lucas Critique was fatal and new approaches had to be developed" (Miller, 1994, xv). The quest for new approaches has been supposedly achieved by today's "New Neoclassical Synthesis" models, i.e. dynamic stochastic general equilibrium (DSGE) models (Smets and Wouters, 2005; Christiano et al., 2005). Such macroeconometric models are considered by most as not vulnerable anymore to the Lucas Critique. This paper challenges this view, and emphasizes how the debate on the interpretation and relevance of the Lucas Critique is still open today. Besides, I argue that this should be understood as the historical result of rival interpretations of Lucas's original paper, and more specifically rival understandings of the relation between the Lucas Critique and the idea of microfoundations 3

Lucas (1976) addresses the following methodological question: How to build macroeconometric models that provide reliable quantitative evaluation of the effects of alternative rules for economic policy? Lucas's answer is: in order to provide a sound expertise, the model parameters must be "structural", i.e their values must be "invariant" with respect to policy changes. In short, parameters must be "stable".

The first claim of my paper is that most DSGE modelers consider that Lucas (1976) describes stability of parameters as an inherent property of models specifying aggregate relations as the result of optimizing, forward-looking individual agents - in short, microfounded models. In a nutshell, most DSGE modelers consider that microfoundations of macroeconomic models imply pa-

1 A standard narrative is a widespread tale about the history of macroeconomics told by practitioners in order to legitimize current standard approach to macroeconomics. For a more comprehensive view see Sergi (2017b).

2 Goutsmedt et al. (2017) challenges this first claim of the standard narrative.

3 Section 1 clarifies that the word "microfoundations" should be understood in the very specific sense of "Lucasian microfoundations". For now, I will use the term microfoundations generically, as it is current in the DSGE literature.

4 Note that we consider, hereafter, stability as the invariance of the parameters values across periods, and not across data sets or estimation methods. 
rameters stability - and, consequently, that microfoundations imply a sound quantitative policy evaluation. For instance, a consumption function describing intertemporal optimization and therefore relying on parameters describing preferences (e.g. subjective discount factor, elasticities of substitution, etc.) should be considered a priori as a stable relationship; conversely, consumption functions relying on non-microfounded parameters - such as the Keynesian marginal propensity to consume - are to be considered by definition as relationships vulnerable to the Lucas Critique.

Michael Woodford, a key figure in the New Neoclassical Synthesis, endorses very clearly this view in his introduction to Interest and Prices:

a model $[\ldots]$ with clear foundations in individual optimization is important, in our view, for two reasons. One is that it allows us to evaluate alternative monetary policies in a way that avoids the flaw in policy evaluation exercises using traditional Keynesian macroeconometric models stressed by Lucas (1976).

(Woodford, 2003, 13)

According to Woodford, microfoundations ("clear foundations in individual optimization") allow to escape the "flaw" of parameters' instability, emphasized by Lucas (1976) in the case of "Keynesian" models. DSGE models are also fashionable among central banks and other policy-making institutions, and macroeconometricians responsible for building such models make a similar claim: DSGE models are not vulnerable to the Lucas Critique because they are microfounded. The following examples, drawn from technical reports about DSGE models (from the Bank of Israel and the Swiss National Bank), illustrate this argument:

Being micro-founded, the model enables the central bank to assess the effect of its alternative policy choices on the future paths of the economy's endogenous variables, in a way that is immune to the Lucas (1976) critique.

(Argov et al., 2012, 5)

[The DSGE] approach has three distinct advantages in comparison to other modelling strategies. First and foremost, its microfoundations should allow it to escape the Lucas $(1976)$ critique.

(Cuche-Curti et al., 2009, 6) 
So it seems that, thanks to microfoundations, the "flaw" of old "Keynesian" models has been eradicated once for all; nowadays, macroeconometric DSGE models are robust to the Lucas Critique and reliable for quantitative policy evaluation.

Yet, in a 2005 interview, Lucas himself argues, sibylline: "I think [the Lucas Critique] has been tremendously important, but it is fading." (Lucas in Snowdon and Vane, 2005, 282). Does Lucas mean that his Critique is losing importance either because all macroeconomists are aware of it, or, conversely, because they forgot its importance? Charles Plosser - a key figure of the real business cycle (RBC) approach in the 1980s - argues indeed that the current DSGE approach forgot about the importance of the Lucas Critique:

In my view, the current rules of the game of New Keynesian DSGE models run afoul of the Lucas critique - a seminal work for my generation of macroeconomists and for each generation since.

(Plosser, 2012, 5)

A quick overview of the most recent articles in the DSGE literature mentioning Lucas (1976) - such as, for instance, Hurtado (2014); Lubik and Surico (2010) or Chang et al. (2010) - confirms Plosser's view: all these contributions claim that DSGE models are vulnerable to the Lucas Critique. Such criticisms come from the inside of the DSGE approach, including the institutions using these models for policy analysis (for instance in the case of Hurtado, 2014).

The very same existence of this debate within the DSGE approach is surprising. How the "consensus" view on macroeconomics (the New Neoclassical Synthesis) could still be in disagreement on such a crucial issue as the soundness of policy evaluation with DSGE models? The purpose of this article is to explain the reasons underlying this lasting and surprising disagreement. My claim is that the current debate about DSGE models and the Lucas Critique should be understood through a historical perspectivenamely, through the development, during the 1980s and 1990s, of two rival interpretations of Lucas (1976). On the one hand, the RBC approach advocated for what I will call a "theoretical interpretation" of the Critique; on the other hand, Keynesians championed what I will call an "empirical interpretation" of the Critique. These interpretations were rival with respect to their assessment of the following proposition: do microfoundations imply parameters' stability?

5 This article scrutinizes a wide range of literature on the Lucas Critique, pertaining 
RBC approach argues that microfoundations do imply parameters' stability. This implies that a macroeconomic model pertains forcefully (logically) to one of the following cases:

Table 1: The theoretical interpretation of the Lucas Critique

\begin{tabular}{c|c|c}
\hline & stability of parameters & instability of parameters \\
\hline microfoundations & yes & \\
\hline no microfoundations & & yes \\
\hline
\end{tabular}

Note that the two alternative cases "no microfoundations-stability of parameters" and "microfoundations-instability" are logically empty sets. Thus providing microfoundations is a sufficient condition to ensure the stability of parameters and, hence, the soundness of a model for quantitative policy analysis.

Conversely, following the empirical interpretation of the Critique, Keynesians argue that microfoundations do not imply parameters' stability. Hence, a macroeconomic model could possibly pertain to any of the four following cases:

Table 2: The empirical interpretation of the Lucas Critique

\begin{tabular}{c|c|c}
\hline & stability of parameters & instability of parameters \\
\hline microfoundations & yes & yes \\
\hline no microfoundations & yes & yes \\
\hline
\end{tabular}

Thus, the parameters' stability could not be determined by assessing the microfounded character of the model - or, in other words, microfoundations are not a sufficient condition for concluding that the model has stable parameters. Therefore, the Lucas Critique is an empirical issue: we should look at parameters' values, using statistical tests, to assess their stability.

Section 1 of this article shortly analyzes Lucas's 1976 article and subsequent works to illustrate how two possible interpretations of Lucas's argument could arise from the original contribution. Section 2 analyzes the theoretical and empirical interpretation of the Lucas Critique arising during

to different eras and approaches, aiming at illustrating the common ground of the discussion and uncovering the points of contention. Therefore, note that the terminology employed here constitute a reappraisal of the actual terms employed by different authors. 
the 1980s. Section 3 illustrates how these two interpretations currently coexist within the DSGE approach, resulting in a fundamental disagreement about the vulnerability of DSGE models to the Lucas Critique, and also a disagreement about the potential solutions to this problem.

\section{The Lucasian interpretation of the Critique}

Lucas (1976) was formulated as a "critique" of what he perceived as the dominant approach to macroeconometric modeling of its time. According to Lucas, models in this approach, issued from the tradition of Klein and Goldberger (1955) - explicitly targeted by Lucas (1976, 19) — "provide no useful information as to the actual consequences of alternative economic policies" (ibid.). Lucas's argument was based on questioning the "stability" of behavioral parameters in those models: their behavioral parameters (say, the marginal propensity to consume) were supposed to be stable across time, whereas they were drifting along with changes in economic policy.

This criticism was far from being new - as Lucas himself acknowledged (ibid., 19, fn.3). ${ }^{6}$ What is new in the Lucas Critique is the diagnosis of the problem. Indeed, Lucas is arguing that macroeconometric models à la Klein and Goldberger (1955) are not structural because

the individual decision problem: "find an optimal decision rule when certain parameters (future prices, say) follow arbitrary paths" is simply not well formulated

$$
\text { (Lucas, 1976, 26). }
$$

According to Lucas, the individual decision problem will be "well formulated" if it was derived, in an hypothetico-deductive perspective, from "microeconomic theory", i.e. neo-Walrasian general equilibrium approach. Lucas criticizes the mainstream macroeconometric approach for relying on econometric induction instead of using "microeconomic theory":

6 The stability of parameters in macroeconometric models has been indeed a main concern for econometricians since the 1930s. For instance, Ragnar Frisch (1938)'s critique against Tinbergen's first macroeconometric model for the League of Nations is based upon the same argument: Frisch pointed out that the parameters used by Tinbergen in his model were not invariant of changes in policy (relationships within the model were not "autonomous" in Frisch's words). Even if Frisch's notion of "autonomy" of macroeconometric models was quickly dismissed (Qin, 2014), econometricians still took seriously the underlying issue - see for instance Tinbergen (1956, Chap. 5), Marschak (1953, 8;25) and Haavelmo (1944, 27). 
[the] micro-economic role for theory [to rationalize individual econometric relationship] abdicates the task of describing the aggregate behaviour of the system entirely to econometricians.

(ibid., 23)

This leads inevitably macroeconometric models to produce predictions that are contradictory with those made by "microeconomic theory": the trade-off between inflation and output is, for Lucas, the perfect illustration of such an "obvious fallacy" (ibid.) with respect to theory.

In a nutshell, Lucas's diagnosis is that the mainstream macroeconometric approach is not useful for policy evaluation because it is driven in the first place by empirical concerns instead of being driven by theoretical rigor. As a result, macroeconometric models lack of "microfoundations", i.e. they do not specify macroeconomic relationships in terms of individual decision rules resulting from the hypotheses of the "microeconomic theory". In Lucas understanding, microfoundations consist in describing macroeconomic (aggregate) phenomena as arising from individual (microeconomic) behavior. The description of microeconomic behavior should rely on (i) intertemporal optimization, (ii) endogenous, forward-looking expectations and (iii) marketclearing (all the individual plans are compatible).7

The logical implication of Lucas's line of argument is that macroeconometric models can perform policy evaluation if their behavioral equations are microfounded. Hence, the Lucas Critique can actually be interpreted as a methodological prescription: even if the initial question addressed by Lucas (1976) is more likely to be resumed as "how not to build macroeconometric models for policy evaluation" (i.e. as a "negative" prescription), the "how to build it" question (i.e. a "positive" prescription) is clearly addressed in the conclusions of the article. Lucas suggests indeed that macroeconometric microfounded models should be formalized as a system of two difference equations:

$$
\begin{aligned}
y_{t+1} & =F\left(y_{t}, x_{t}, \theta(\lambda), \epsilon_{t}\right) \\
x_{t} & =G\left(y_{t}, x_{t-1}, \lambda, \eta_{t}\right)
\end{aligned}
$$

Equation (1) describes the law of motion of the economic system ( $y_{t}$ being the endogenous variables, $x_{t}$ the exogenous variables and $\theta(\lambda)$ a vector of individual decision rules for a given set of behavioral parameters). Equation

7 Such "Lucasian microfoundations" must be distinguished from other "microfoundational programs" (see Hoover, 2012). Hereafter I will simply use the term "microfoundations", in short, instead of "Lucasian microfoundations". 
(2) represents the evolution of the exogenous variables, with $\lambda$ a vector of parameters, including those describing policy rules ( $\epsilon, \eta$ are i.i.d disturbances). The Lucas Critique targeted models that use fixed behavioral parameters $\theta$, instead of using decision rules $\theta(\lambda)$, taking into account the evolution of individual behavior in response to changes in the environment. 8 For instance, a model formalizing consumption behavior based on a fixed marginal propensity to consume (agents consume a fixed share of their current income) will ignore, according to Lucas, the fact that this marginal propensity depends, for instance, on the preferences toward future consumption. Therefore, marginal propensity to consume is not a "stable" parameter (or "deep structural" in Lucas's terminology) — while a subjective discounting factor is.

Lucas (1976) does not provide any empirical evidence to support its claim - neither econometric tests nor statistical analysis of parameters' instability in Keynesian models $9^{9}$ Thus, one could legitimately consider - and the RBC approach will - that the Lucas Critique is a theoretical argument of the kind "microfoundations imply parameters' stability".

However, if one takes a broader look at Lucas's work, another interpretation of the Critique arises. Lucas and Thomas Sargent, in their famous "After Keynesian Macroeconomics", did emphasize very explicitly that the stability of parameters should be "an empirical question, and not a theoretical one":

[there is] a number of theoretical reasons for believing that the parameters identified as structural by the methods which are in current use in macroeconomics are not structural in fact. That is, there is no reason, in our opinion, to believe that these models have isolated structures which will remain invariant across the class of interventions that figure in contemporary discussions of economic policy. Yet the question of whether a particular model is structural is an empirical, not a theoretical one.

$$
\text { (Lucas and Sargent, 1979, 56). }
$$

Moreover, they admit that the Lucas Critique was an argument driven by "theoretical reasons" or "theoretical objections", and therefore it can possibly be refuted empirically (even if they do not think this will be the case):

8 Note that, according to Lucas, only changes in policy rules can be addressed with this approach: evaluating discretionary policies is still "beyond the capability not only of the current-generation models, but of conceivable future models as well" (ibid., 41-42).

9 Note that Lucas disagrees with this assessment, arguing that the three analytical examples developed in section 5 of his paper are "empirical evidences" (Letter from Lucas to Stanley Fischer, 17/11/1981; Lucas Archives, Box 5, Folder: 1982 1/2). 
If macroeconometric models had compiled a record of parameter stability, particularly in the face of breaks in the stochastic behavior of the exogenous variables and disturbances, one would be skeptical as to the importance of prior theoretical objections of the sort we have raised.

(ibid.).

Later on, when introducing his collected works in Studies in Business Cycle Theory, Lucas argues again:

this presumption [about policy-invariance] seems a sound one to me, but it must be defended on empirical, not logical grounds, and the nature of such a defense presumably would vary with the particular application one has in mind.

(Lucas, 1981, 11-12)

This call for empirical work on the Lucas Critique has been indeed answered by the new Classical macroeconometric approach (Lucas and Sargent, 1981). This approach aims indeed at implementing econometric procedures for specification and identification of models that will abide by the theoretical standards set by the Lucasian microfoundational program. More specifically, as summarized by Lars Hansen and Sargent in their emblematic contribution, this line of work consists in "estimating agent's decision rules jointly with models for stochastic processes they face, subject to cross-equation restrictions implied by the hypothesis of rational expectations" (Hansen and Sargent, 1981, 7-8). Using the above notation, the scope of new Classical macroeconometrics is (i) to specify the decision rules $\theta(\lambda)$ (equation 1 ); (ii) to identify the parameters $\lambda$ that govern the exogenous process in the economy (equation 2); (iii) to identify the "deep" parameters of the decision rules; and (iv) to run estimations for equations (1) and (2), with cross-equations restrictions 10 The new Classical macroeconometric approach should be regarded as a consistent extension on empirical ground of the Lucas Critique as a methodological prescription.

This section raised two crucial issues. Firstly, Lucas (1976) in itself is presented as a theoretical argument; secondly, Lucas himself in later work and, most prominently, the new Classical macroeconometric approach, tackled the issue raised by Lucas (1976) with empirical methods. This state of affairs provides a background for the development of two rival interpretations of the Critique during the 1980s.

${ }^{10}$ For an extensive account about new Classical macroeconometrics see Sergi (2015) and Sergi (2017a, Chap. 2). 


\section{Two rival interpretations of the Lucas Cri- tique}

\subsection{The theoretical interpretation of the Lucas Critique by the RBC approach}

The RBC approach championed what I will call a theoretical interpretation of the Lucas Critique. This is to say, that Kydland, Prescott and the other RBC macroeconomists interpreted Lucas (1976)'s argument as "microfoundations imply empirical stability".

This interpretation is rooted in Kydland and Prescott (1977) - thought this work precedes the development of RBC models (Kydland and Prescott, 1982) - where the authors endorse Lucas's criticism of "standard" macroeconometrics:

Standard practice is to estimate an econometric model and then, at least informally, to use optimal-control-theory techniques to determine policy. But as Lucas (1976) has argued, since optimal decision rules vary systematically with changes in the structure of series relevant to the decision maker, any change in policy will alter the structure of these rules.

$$
\text { Kydland and Prescott, 1977, 474) }
$$

Moreover, Kydland and Prescott claim that models vulnerable to the Lucas Critique (namely, macroeconometric models à la Klein and Goldberger, 1955) actually led to "bad" policy recommendations (namely, expansionary monetary policy) and, finally, to "perverse" economic outcomes (namely, U.S. 1970s stagflation) 11

[Thus, we found that] stabilization efforts have the perverse effect of contributing to economic instability. [...] In effect the policymaker is failing to take into account the effect of his policy rule upon the optimal decison [sic] rules of the economic agents.

(ibid.)

Kydland and Prescott want to avoid such a fallacious misuse of macroeconometric models for policy analysis. Thus, they argue that models should be used for policy evaluation only if they provide corroborated ("tested") predictions:

11 This is what Snowdon (2007) calls the "idea hypothesis". For a discussion about this interpretation of Lucas (1976), see Goutsmedt et al. (2015, 18-20). 
a tested theory ${ }^{12}$ of economic fluctuations [is] something which is needed before policy evaluation is undertaken. The implication of [our] analysis is that, until we have such a [tested] theory [of economic fluctuations], active stabilization may very well be dangerous and it is best that it not be attempted.

(ibid., 487)

The important claim made here by Kydland and Prescott is that building models for policy analysis is a two-step procedure: first, one must provide a "tested" model of the business cycle; then, one can use this "tested" model for policy evaluation. This distinction constitutes a crucial turn in the further development of the RBC assessment of the Lucas Critique ${ }^{13}$

The first step ("testing") consists in building a model whose simulated dynamic would correspond with observed time series of main aggregates. Kydland and Prescott's purpose in their 1982 seminal article is to complete this first step, namely to build "a general equilibrium model" that would "fit the U.S. quarterly data for the post-war period" (Kydland and Prescott, 1982, 1345). Consistently with the idea of a two-step work, Kydland and Prescott original RBC model did not include any policy consideration: indeed, policy and policy-makers are simply not formalized. Moreover, the same remark applies to the two other seminal contributions of the RBC approach, namely to Long and Plosser (1983) and to Black (1982).

However, as long as the model fits data, it is supposed to have been "tested": thus, it could be used in the second step of macroeconomic analysis, i.e. policy analysis. Despite not having specified or tested any decision rule linking individual private agents behavior to the policymaker choice (as did the new Classical macroeconometric approach) Kydland and Prescott argue very clearly that their 1982 model without policy is viable for policy analysis:

Models such as the one considered in this paper could be used to predict the consequence of a particular policy rule upon the operating characteristics of the economy.

(Kydland and Prescott, 1982, 1369)

\footnotetext{
12 Note that Kydland and Prescott use with no distinction the word "theory" to mean "model". On this issue, they follow Lucas ("I mean theory in the sense of models", Lucas, 1987, 2).

13 This distinction is actually quite close to the one set by Lucas himself, in order to provide "scientific" expertise - contrasting with "ideology" (De Vroey, 2011). As pointed out by De Vroey (2015, chap. 13) and as I will illustrate here, Kydland and Prescott departed then from Lucas's view about how to implement such a distinction.
} 
The following argument supports their claim:

As we estimate ${ }^{14}$ the preference-technology structure, our structural parameters will be invariant to the policy rule selected even though the behavioral equations are not.

(Kydland and Prescott, 1982, 1369)

This is the crucial argument illustrating Kydland and Prescott's theoretical interpretation of the Lucas Critique. They argue that the "preferencetechnology" structure is a sufficient condition for parameters stability ("invariance to policy"). This is to say, that the parameters characterizing preferences and technologies in their model are a priori policy-invariant, stable parameters.15 Thus, we can read Kydland and Prescott's argument as a claim that "microfoundations imply empirical stability".

This claim is supposed to be "tested" indirectly, by illustrating the fit between model's simulation and observations. Hence, there is no direct empirical investigation of the stability of the parameters characterizing preferences and technologies. Moreover, the the "calibration" method pioneered by Kydland and Prescott relies entirely on this conception of microfoundations as a priori policy-invariant parameters. Indeed, as the values of such parameters are supposed to be stable across time (and across policy regimes), these values can picked up once-for-all relying on different sources. This includes: (i) a set of evidences produced outside the model (for instance in microeconomic literature); (ii) a "plausible" value to the subjective judgment of the modeler; (iii) a set of calibration values in other RBC models. ${ }^{16}$ Such a procedure becomes meaningful only because microfounded parameters such as preferences and technologies are assumed a priori as stable. Thus, there is no need to provide any direct empirical evidence about stability within the model. In this sense, despite mentioning the importance of a "tested" theory, Kydland

\footnotetext{
14 Rather read "calibrate".

${ }^{15}$ Formally, referring to equations $(1-2)$ above, Kydland and Prescott suggest that preferences and technologies are parameters in the vector $\theta$ that are fixed and independent from the policy components of $\lambda$. For instance, subjective discount factor $\beta$, describing agent's preferences toward the future, would be, by definition, a stable parameters, i.e. invariant of, say, changes in monetary policy rules. This claim is obviously consistent with core assumptions of general equilibrium approach, where preferences are always given (exogenous and fixed).

${ }^{16}$ An insightful comment about this is Kydland and Prescott's later claim that "because the language used in these business cycle models is the same as that used in other areas of applied economics, the values of common parameters should be identical across these areas and typically have been measured by researchers working in these other areas" (Kydland and Prescott, 1991, 170, my emphasis).
} 
and Prescott interpret the Lucas Critique as a theoretical proposition of the kind "microfoundations imply stability".

In a nutshell, the Kydland and Prescott (1982)'s interpretation of the Lucas Critique relies on the two-step procedure which they had formulated in their 1977 paper: (1) indirectly corroborating the policy-invariance of microfounded parameters (those characterizing preferences and technology, e.g. elasticities), in a framework without policy; (2) using a model with these very same parameters for policy analysis. Policy evaluation exercises in further RBC literature follow this procedure. Contributions like Cooley and Hansen (1989) and Greenwood and Huffman (1991) provide two illustrations. ${ }^{17}$ Cooley and Hansen (1989) try to evaluate the effects on welfare of different levels of inflation volatility (corresponding to different monetary policy), using a calibrated RBC model with cash-in-advance transaction functions. Greenwood and Huffman (1991) run a similar welfare analysis for different fiscal policies. The most complete synthesis of this line of work is Chari et al. (1995), addressing directly the question of optimal monetary policy rules. All these authors addressed the policy evaluation following the Kydland and Prescott assessment of the Lucas Critique: specifying microfoundations, i.e. specifying preferences and technology, is a sufficient condition for escaping the Lucas Critique. Therefore, models are built assuming that preferences and technology are characterized by policy-invariant parameters, and their values are calibrated using values of previous RBC models.

Note that, especially during the 1990s, such a theoretical interpretation of the Lucas Critique was criticized inside and outside the RBC approach. For instance, within the RBC approach, Danthine and Donaldson $(1993,17)$ wonder "to what extent do the benchmark stylized facts used in the literature depend upon the selection of time periods or variations in policy regimes". Outside the RBC approach, the criticisms are of course more radical. In "Post-econometric Policy Evaluation: A Critique", Beth Ingram and Erich Leeper argue that RBC models repeat 'the 'Keynesian' errors that Lucas (1976) noted in its influential critique" (Ingram and Leeper, 1990, 1). According to the authors, this is mainly due to two errors: first, the fact that all $\mathrm{RBC}$ literature on policy evaluation uses parameters' values for calibration that are borrowed from previous RBC models, with no policy considerations; second, the fact that RBC models don't specify explicitly how individual decision rules depends on policy. This criticism is a useful in uncovering the theoretical interpretation of the Lucas Critique underlying the RBC models.

\footnotetext{
${ }^{17}$ Another strain of works in RBC approach, which I will not analyze here, studies policies (tax policies or government spending) as additional sources of the business cycle fluctuations (Braun, 1994, Christiano and Eichenbaum, 1992, McGrattan, 1994).
} 
In extenso:

Frequently, RBC modelers transport the parameter values Kydland and Prescott used in their model without policy to the new model with policy. [...] Kydland and Prescott's model assume that policy doesn't affect private decision rules. There is no policy evaluation to perform. Alternatively, if policy does affect private behavior, then the parameters Kydland and Prescott calibrate are reduced-form parameters for some underlying model embedding monetary and fiscal policy. Thus, if there is any policy evaluation left to perform, Kydland and Prescott's calibrated parameters must be functions of policy behavior and should change systematically with policy. When RBC modelers evaluate alternative policies, however, the calibrated parameters are held fixed.

(ibid., 3-4, their emphasis)

\subsection{The empirical interpretation of the Lucas Critique}

Conversely to Kydland and Prescott, many macroeconomists understood Lucas (1976) as an invitation to investigating empirically - through econometric tests or statistical analysis - the stability of parameters in macroeconometric models. This is what I will call the "empirical interpretation" of the Lucas Critique. Following this understanding, Lucas's argument would not forcefully result in a theoretical reformulation of macroeconometric models (favoring microfoundations); to the opposite, Lucas's argument primarily imply an empirical, econometric footwork investigating the actual invariance of parameters'. Depending on the results of such investigations, the need for microfoundations could be either corroborated or rejected.

As we illustrated in details in Goutsmedt et al. (2017), the empirical interpretation of the Lucas Critique was, during the 1980s, a common ground to different generations of Keynesians and to time-series econometricians.

Note that the label "Keynesian" is generic and it covers indeed a wide range of authors and modeling practices. As a first approximation of the different groups that would be associated to this label, let consider that it refers to two different generations, "old" and "young" Keynesians.

Old Keynesians developed during the 1950s and 1960s the kind of large scale macroeconometric models à la Klein and Goldberger (1955) which were directly targeted by the Lucas Critique. Prominent figures of this generation includes for instance Lawrence Klein, Franco Modigliani, James Tobin, Robert Solow or Edmond Malinvaud. Overall, their reaction to the Lucas Critique was of strong rejection, based on lack of empirical evidence. Old 
Keynesians argued that the Lucas Critique was not a relevant argument, so far that Lucas and new Classical did not show econometric evidence of the instability of parameters in non-microfounded macroeconometric models. However, old Keynesians did not directly engaged in empirical work about the Lucas Critique, considering that the burden of proof rested on new Classical macroeconomists. Still, it is much clear that they interpret the Critique as an empirical question.

The younger Keynesian generation shared with the old Keynesians the same interpretation of the Lucas Critique as an argument that lacked of empirical support. Alain Blinder is quite representative of this view when he argues:

All you have to do in this country [...] right now is scream mindlessly, "Lucas critique!" and the conversation ends. That is a terrible attitude. The Lucas critique may be correct, but I have seen no persuasive evidence in any sphere to indicate that it is empirically important. The empirical case is yet to be made.

$$
\text { (Blinder in Klamer, 1984, 166) }
$$

However, this younger generation had a different approach to the debate than the old Keynesians: they directly addressed the issue of parameters stability with their own empirical work (as Blinder, 1979 did). The most insightful illustration of this approach is Olivier Blanchard's "The Lucas Critique and the Volcker Deflation" (Blanchard, 1984), ${ }^{18}$ In this paper, Blanchard investigates two traditional macroeconomic relationshipsthe Phillips curve and the term structure of interest rates - in a context of change in policy regime - namely, the U.S. monetary policy after 1979.19 The Phillips Curve and the term structure analyzed in the paper are those used in macroeconometric models à la Klein and Goldberger (1955), both specified with backward-looking expectations, so non-microfounded in the Lucasian sense.20 The purpose of Blanchard's empirical study is to find out if the parameters characterizing these relationships are stable despite the change in policy regime. Results are obtained by first estimating the relations for the period preceding the change in monetary policy, then by re-estimating the same relation introducing additional years after the change. Fisher tests reveal instability in parameters' for the term structure, but not for the Phillips

18 Similar studies are Englander and Los (1983) and Taylor (1984).

19 Paul Volcker's appointment as chairman of the Federal Reserve in August 1979 brought to a tightening of monetary policy and to a switch to inflation targeting as policy objective.

20 The Phillips Curve is taken from the DRI model used by the U.S. Congress Budget Office, and the term structure from the MPS model of the Federal Reserve Board. 
curve: thus, the Lucas Critique is empirically relevant to the former, but not to the latter.

Thus, Blanchard (1984)'s result suggests that, in some cases (e.g. the term structure), the absence of microfoundations implies parameters instability. This kind of evidence provided an additional rationale for a Keynesian line of work embracing Lucas's microfoundations. This line of work is commonly labeled "new Keynesian economics" (Mankiw and Romer, 1991), and it covers a wider range of modeling practices, all inspired from very different seminal contributions.

A common ground to new Keynesians is that they accepted indeed to formulate their models under the form of optimizing, forward-looking behavior of the economic agents - abiding by Lucas's principle of microfoundations. Moreover, new Keynesians referred to the Lucas Critique as a justification for their use of microfoundations. Early contributions to the new Keynesian literature illustrate this view. Michael Parkin, the first author to label his own work as "new Keynesian" (according to Gordon, 1990, 1115, fn. 2) suggests that Lucas Critique is an important standard for assessing his work:

[My paper] extends earlier work on the microeconomic foundations of sticky prices [...] Hence, this paper is able to go much further in meeting the Lucas (1976) critique than earlier macromodels with price (or wage) rigidities.

(Parkin, 1986, 200-201)

Ben Bernanke, another key figure in the new Keynesian approach, supports that a "virtue" of a model consists in its robustness to the Lucas Critique:

[My model's] virtue is that it permits estimation to be based on the closed-form solution to a dynamic stochastic optimization problem, which leads to maximum efficiency in the use of the data. The estimation procedure employed here is not vulnerable, as those in some earlier studies are, to the criticisms made by Robert Lucas (1976).

(Bernanke, 1983, 71)

Finally, it is important to note that the Keynesian empirical interpretation of the Lucas Critique was shared during the 1980s by Christopher Sims and LSE time-series econometricians. This approach resulted from Sims (1980)'s claim that macroeconometric models should rather rely on hypotheses inducted from the econometric evidence than on a priori hypotheses deduced from economic theory. Consistently with this view, Sims (1982)'s reply to Lucas (1976) echoed old Keynesians arguments. Sims argues that the 
Lucas Critique could not be hold as relevant a priori: the stability of parameters must be investigated empirically; microfoundations cannot be considered as implying stability. More specifically, Sims raised two objections against the Lucas Critique: (i) changes in rules represent a very negligible aspect of actual policy-making, so that the scope of the Critique is a very narrow one; (ii) traditional macroeconometric models still perform very well for econometric policy evaluation, and Lucas did not bring any empirical evidence against them. LSE econometric tradition led by Denis Sagan and David Hendry later developed Sims's view about the Lucas Critique ${ }^{21}$ Similarly to the younger Keynesian generation, LSE econometricians directly engaged in empirical investigation about the stability of parameters. Their works (see especially Ericsson and Irons, 1995) rejected as well the relevance of Lucas's argument and developed an alternative, statistical definition of stabilitythe notion of "superexogeneity" (Engle et al., 1983). This line of work is still active today and criticizing the DSGE approach on the same ground, arguing that

the use of the word 'structural' to describe an equation or a subset of a model has been hijacked by followers of Lucas (1976) away from its original meaning of invariant to shifts elsewhere in the system to mean 'microfounded'. But rationalization in terms of optimizing behaviour does not guarantee invariance, nor is it true that invariance always fails in models where such microfoundations are lacking.

(Hendry and Muellbauer, 2018, 294)

\section{The DSGE models and the Lucas Critique}

The previous section discussed the two interpretations of the Lucas Critique arising in the 1980s. The RBC approach interpreted the Critique as a theoretical argument: microfoundations (intended as specifying preferences and technologies) were, a priori, a sufficient condition to perform quantitative policy evaluation - in short, microfoundations imply a priori the empirical stability of parameters. Conversely, the Keynesian approach interpreted the Critique as an empirical argument about the stability of parameters; consequently, they considered that only statistical observations and econometric tests (and not theory) allow to distinguish between stable and unstable parameters and, eventually, to justify the use of microfoundations for quantitative policy evaluation.

${ }^{21}$ For an historical perspective on this approach, see Qin (2013, Chap. 4) and Spanos (2014). 
My claim is that this two rival interpretations are still the underlying framework of the current debate about the Lucas Critique within the DSGE approach. In my introduction ( $c f$. infra), I have already mentioned a number of contributions to this literature that are evidently consistent with the theoretical interpretation of the Critique - as for instance, Argov et al. (2012, 5) arguing that "being microfounded [...] DSGE models are immune to the Lucas Critique". I will not comment further on this kind of argument. ${ }^{22}$ Conversely, the purpose of this section is to scrutinize the DSGE literature emphasizing the vulnerability of these models to the Lucas Critique.

The current debate about DSGE models and the Lucas Critique is frequently reviewed with different categories: Hurtado (2014) for instance classifies the arguments into "theoretical" and "empirical" critiques; Inoue and Rossi (2008) distinguish between "specification" and "identification" critiques. My paper already provided a historical perspective on these classifications, explaining how "theoretical" ("specification") and "empirical" ("identification") criticisms arose from two past interpretations of Lucas (1976). Moreover, the decisive point made by this section is about the research perspectives which will be associated with two different kind of criticism. My claim is that DSGE modelers sharing a theoretical interpretation of the Critique will support a "not-enough-microfoundations" perspective: providing "more microfoundations" to DSGE models will solve the problem of their vulnerability to the Lucas Critique. Conversely, DSGE modelers endorsing the empirical interpretation of the Critique will back a "microfoundations-arenot-enough" perspective: pragmatical, empirical choice of parameters and alternative microfoundations - meaning "non Lucasian microfoundations" - are the only viable solution to the problem. Thus, these different perspectives would eventually develop divergent research paths for DSGE models, introducing a breakthrough in the "New Neoclassical Synthesis".

\subsection{Are DSGE models "enough" microfounded?}

As already mentioned in the introduction, Plosser recently pointed out how DSGE models are vulnerable to the Lucas Critique. According to Plosser, this weakness results from the new Keynesian elements of DSGE models, such as price and wage rigidities. Indeed, these elements lack of microfoundations, as they are not specified in terms of optimizing individual behavior:

When the real and nominal frictions of New Keynesian models do

\footnotetext{
${ }^{22}$ In Goutsmedt et al. (2017, sect. 1) we made a similar point about the interpretation of the Lucas Critique as "a syllogism".
} 
not reflect the incentives faced by economic actors in actual economies, these models violate the Lucas critique's policy invariance dictum, and thus, the policy advice these models offer must be interpreted with caution.

(Plosser, 2012, 5)

Consequently, Plosser considers that, in order to preserve DSGE models from the Lucas Critique, "we should work to give the real and nominal frictions [...] deeper and more empirically supported structural foundations" (ibid., $6)$.

Many contributions in the current debate will follow this argument, which is inherited from RBC assessment of the Lucas Critique as we described it in sub-section 2.1. I will illustrate this claim commenting four examples (Lubik and Surico, 2010; Inoue and Rossi, 2008; Fernández-Villaverde and Rubio-Ramirez, 2007 and Chari et al., 2008). The core argument of these contributions is that such a vulnerability result from unsatisfactory microfoundations of some parameters in the DSGE, especially price and wage rigidity and monetary policy rules. This features are considered as not "enough" microfounded, because they are not explicitly derived from an optimizing, forward-looking behavior. As a consequence, the related parameters are not stable. To solve the problem, one need to provide "more" microfoundations to DSGE models.

Conversely to the RBC literature, DSGE modelers engaged directly in producing empirical evidence about the relation between microfoundations and stability. Lubik and Surico (2010) is a perfect illustration of this change of attitude: the article challenges explicitly econometric tests of the Lucas Critique in the 1980s and 1990s - such as Blanchard (1984) the "superexogeneity" tests (Ericsson and Irons, 1995) - as well as their more recent versions (Estrella and Fuhrer, 2003; Rudebusch, 2005). According to Lubik and Surico, these tests are simply "not well formulated', as they investigate only the variation of the values of the parameters in reduced forms, relying on Fisher tests. Thus, the results of the Fisher tests could be biased (the power of the test being artificially high) if there is a increasing variability of error terms of the reduced forms. Hence, Lubik and Surico suggest that a "proper" test of the stability of parameters should first investigate the homoscedasticity of residuals to ensure reliability of Fisher tests. In their paper, they illustrate indeed that, in the case of non-microfounded models, this empirical method of investigation comes to the result that "the Lucas critique is alive and well" (Lubik and Surico, 2010, 179). This results corroborate then the idea that microfoundations are a necessary condition for stability. Relying 
on this proposition, Lubik and Surico argue that DSGE models equally fail in escaping the Lucas Critique because they lack of microfoundations, as they rely on "ad hoc" monetary policy rules:

A deeper issue is whether DSGE models that are used for policy analysis are not themselves subject to the Lucas critique. Implicitly, Lucas's argument rests on the notion that the information set of economic agents and their decision problems were not fully specified in traditional macroeconometric models. Yet, with the use of ad hoc monetary policy rules, that very issue surely comes up in DSGE models that do not include optimizing policy makers.

(Lubik and Surico, 2010, 192)

In a similar vein, "How Structural Are Structural Parameters?" (Fernández-Villaverde and Rubio-Ramirez, 2007) tries to verify empirically: "how stable over time are the so-called "structural parameters" of dynamic stochastic general equilibrium (DSGE) models?" (ibid., 3). The authors rely this time on Bayesian methods and the simulation of a baseline DSGE model. Their strategy is to compare the outcomes of two different simulations. In the first one, the model is simulated but imposing, as a restriction, a fixed value for each parameter. In the second type of simulation, drifts in parameters' values are allowed. Comparing the resulting simulations, the second type better correspond to the observed series of data.

This results lead the authors to conclude that the main source of instability in DSGE parameters is the misspecification of the underlying economic relationships in terms of optimal decision rules. According to the simulation results, the most problematic parameters (those that are more likely to drift) are those describing price adjustments. Thus, the lack of microfoundations is a particular concern for the price-setting behavior specified in the model:

We consider our findings to be strong proof of the changing nature of the nominal rigidities in the economy and of a strong indication of model misspecification along the dimension of price and wage adjustment. Calvo's price adjustment cannot capture the evolution of the fundamentals that determine the pricing decisions of firms and households.

(ibid., 32)

In a nutshell, the vulnerability of the DSGE models to the Lucas Critique is, according to the authors, a consequence of the lack of microfoundations of 
the price-setting behavior à $l a$ Calvo (1983), which specify no endogenous decision about timing of price change. Indeed, the pricing mechanism described by Calvo and universally used in modern DSGE models does consider that economic agents are allowed to change their prices with a given, fixed probability $\beta$. According to Fernández-Villaverde and Rubio-Ramirez (2007), this mechanism does not abide by the microfoundations standards $\grave{a}$ la Lucas, as $\beta$ does not results from an optimization process. In further comments, Fernández-Villaverde and Rubio-Ramirez (2007, 33) also target (like Lubik and Surico, 2010), the monetary policy reaction function à la Taylor (1993), as not derived from an explicit optimizing problem of the monetary authority. Thus, the Taylor rule (and its variations used in the DSGE literature) relies on ad hoc sensibility parameters.

This explanation of the vulnerability to the Lucas Critique as a consequence of the lack of microfoundations leads, logically, to support "more microfoundations" for the DSGE models. As summarized by Inoue and Rossi (2008), "the [unstable parameters] are the potentially misspecified features that require further theoretical modeling efforts" (Inoue and Rossi, 2008, 2). Fernández-Villaverde and Rubio-Ramirez (2007) for instance argue that state-dependent decision rules on price adjustment à la Caplin and Spulber (1987) should be preferred over the Calvo pricing. Similarly, an explicit decision rule for central banks, grounded on optimization under constraint of some policy-target function should be developed as an alternative to Taylor rules (ibid.).

"New Keynesian Models: Not Yet Useful for Policy Analysis" (Chari et al., 2008) illustrates this view eve more explicitly than Fernández-Villaverde and Rubio-Ramirez (2007) and in Lubik and Surico (2010). Chari and co-authors engage in a full-range attack against the full set of market imperfections and rigidities that are distinctive of the DSGE approach. Their empirical strategy consist in showing observational equivalence between different specifications of the most important shocks and parameters on wages, prices and mark-ups. This demonstration aims at concluding that these features are reduced-forms and not "structural" - as a consequence, the related parameters are likely to be unstable across policy regimes.

Shocks on wage-markup for instance are reduced forms and not structural to the extent there is any way of distinguish between two possible causes: a change in the value of leisure or a change in the bargaining power of workers. Hence, according to the authors, the lack of information about the optimization problem underlying markups is responsible for the vulnerability of DSGE to the Lucas Critique. The more general conclusion is that DSGE models are currently flawed because of the incautious addition of new Keynesian features: 
Most of our disagreement stems from our different preferred traditions of model building and assessment. [...] The urge to improve the macro fit leads researchers in the [new Keynesian] tradition to add many shocks and other features to their models and then to use the same old aggregate data to estimate the associated new parameters. This tradition does not include the discipline of microeconomic evidence; so free parameters commonly abound in New Keynesian models.

$$
\text { (Chari et al., 2008, 2) }
$$

Consequently, Chari and his co-authors suggest that the solution to the problem is to provide "more" microfoundations to the DSGE models, by going back to a more rigorous theoretical justification of DSGE specification, in obedience of the Lucasian microfoundational program (ibid., 24).

These four examples illustrated how the theoretical interpretation of the Lucas Critique ("microfoundations imply stability") constitutes an underlying framework for a group of authors criticizing the DSGE approach. However, even if the argument is similar to its 1980s counterpart, it relies today on empirical evidences, directly investigating the stability of parameters. Consistently with the theoretical interpretation of the Critique, this group of authors suggests a way out that implies "more microfoundations", meaning a deeper theoretical specification of some features (rigidities, monetary policies).

\subsection{Are microfoundations "enough"?}

The second strain of literature about DSGE models and the Lucas Critique follows the empirical assessment of Lucas (1976): microfoundations do not imply stability; the stability of parameters could only be assessed by econometric testing. In the early DSGE literature, this line of argument has been followed by Ireland (2004), who argues very clearly that, even in DSGE models, the relation between microfoundations and stability should be empirically investigated, and not simply postulated as in the RBC approach:

One great strength of the real business cycle model is that it is supposed to be structural: it links the behavior of aggregate output and employment describing private agents' tastes and technologiesparameters that ought to remain constant, even across periods when monetary and fiscal policy regimes change. [In this paper], a hybrid [DSGE] model can be used to test the hypothesis that these structural parameters do, in fact, appear stable over time. 
(Ireland, 2004, 1215)

By comparing two periods (before and after the Volcker deflation), Ireland illustrates that there is indeed a change in the value of different parameters of his DSGE models, including those characterizing the preferences and the technologies (Ireland, 2004, 1215-1216).

As in the previous sub-section, I will comment on four examples (Cogley and Yagihashi, 2010, Estrella and Fuhrer, 2003, Hurtado, 2014 and Chang et al. 2010) illustrating how this view is currently adopted in the debate about the DSGE models and the Lucas Critique.

First, it is important to emphasize that current debates about the DSGE models does not exactly address the same question than their 1980s Keynesian ancestors.23 While the latter wanted to demonstrate that nonmicrofounded parameters could be stable, the current debate address the opposite question: are microfounded parameters of DSGE models not stable? The resulting argument is that (Lucasian) microfoundations are not "enough" for ensuring stability. "Are DSGE Models Approximating Invariant to Shifts in Policy?" (Cogley and Yagihashi, 2010) illustrates this evolution: the article does not reject the empirical relevance of the Critique, to the extent it admits that shifts in non-microfounded parameters do occur. However, it suggests that, even if parameters are not stable, their changes do not introduce a relevant bias in the quantitative policy evaluation (measured by the value of a loss function for the policymaker). Consequently, the authors conclude that a complete specification of microfoundations is quite unnecessary, because policy evaluation is "approximately" invariant of change in policies. This conclusion follows the empirical interpretation of the Lucas Critique, furthermore adding a pragmatic argument about the actual feasibility of the Lucasian methodological prescription: "we merely hope to put the Lucas critique in perspective and to reiterate Milton Friedman's precept that the best (in this case, an unattainable ideal) should not be an enemy of the good" (ibid., 29).

In a similar vein, "Monetary Policy Shifts and the Stability of Monetary Policy Models" (Estrella and Fuhrer, 2003) starts by accepting the vulnerability of non-microfounded models to the Lucas Critique as an empirically

\footnotetext{
${ }^{23}$ I will not comment here about few contributions, like for instance Rudebusch (2005), sharing the very same motivation and providing the very same results than those presented in section 2.2. Similarly, I will not address some recent works by time-series econometricians in the line of Ericsson and Irons (1995), such as Juselius and Franchi (2007): these works are external criticisms of the DSGE approach, and I am interested here into the debates within the DSGE literature.
} 
relevant argument. But it rejects the idea that this argument can provide any evidence that microfounded models are robust to the Critique:

But just as the backward-looking models cannot be known to be subject to the Lucas critique a priori, neither can these optimizing models be known to be stable across policy regimes a priori.

(ibid., 95)

The aim of the article is then to provide an empirical test of the Lucas Critique, as in the Keynesian literature analyzed in sub-section 2.2. However, this empirical test will not concern non-microfounded models, but DSGE models, supposed to be firmly microfounded: ${ }^{24}$

In this paper, we present evidence that shows that some monetary policy models from the recent literature, based on optimization and rational expectations, may be less stable in the face of monetary regime shifts than their better-fitting backward-looking counterparts.

(ibid.)

The authors claim that their results lead to the conclusion that microfounded DSGE models shows instability of parameters, to the extent the parameters values are drifting along with changes in policy regimes. In one word, DSGE models behave just as the traditional macroeconometric models criticized by Lucas (1976).

Similar conclusions are suggested in "DSGE Models and the Lucas Critique" (Hurtado, 2014). Hurtado provides evidences that most of the parameters in a benchmark DSGE model (Smets and Wouters, 2005), including those characterizing preferences and technologies, are actually not stable across time. To illustrate more clearly that this implies DSGE vulnerability to the Lucas Critique, Hurtado assess the DSGE performance in policy evaluation compared with traditional macroeconometric approach: do the Smets-Wouters model give a better policy advice than an "old-style" Phillips Curve? The test is run with 1970s' data, a persuasive manner to compare the claim about an "econometric failure on a grand scale" (Lucas and Sargent,

24 "By uncovering the structural parameters that characterize these fundamental behaviors, and by explicitly modeling expectations (usually assuming rational expectations), one may capture the (presumed) dependence of agents' behavior on the functions describing policy" (ibid., 94). 
1979 , 6) with the claim about DSGE robustness to the Lucas Critique. ${ }^{25}$ The result of this comparison confirms that microfounded DSGE and traditional macroeconometric models display the same weakness in terms of policy evaluation:

in terms of parameter invariance and its effect on econometric policy evaluation, the estimated DSGE model would not have done a lot better than the old-style Philips curve. [...] the lesson that policymakers would have drawn from Smets-Wouters are not fundamentally different from those they were extracting from their reduced-form models.

$$
\text { Hurtado, 2014, p18-19) }
$$

Finally, "Labor-market Heterogeneity, Aggregation, and the Lucas Critique" (Chang et al. 2010) aims at dismissing especially the Lucasian microfoundations as a necessary condition for policy evaluation. Following the new Keynesian assessment of the Lucas Critique, the authors run an empirical test of the stability of microfounded parameters in DSGE models, such as preferences and technologies, supposed to be policy-invariant. The result, as in the previous contributions scrutinize infra, is that "preference and technology parameter estimates are not invariant with respect to policy changes" (Chang et al. 2010, 1). The explanation of this vulnerability of DSGE models to the Lucas Critique addresses the representative agent hypothesis, a core assumption in current interpretation of Lucasian microfoundations. According to the authors, the "aggregative function", i.e. the way of aggregating individual behaviors, is likely to be changing along changes in policy. Hence, the microfoundational program built upon the representative agent hypothesis is the reason of the observed instability: "We demonstrate that the representative agent model that abstracts from cross-sectional heterogeneity can potentially mislead fiscal policy predictions" (ibid., 28). Even if this result could be interpreted as an argument in favor of "more" microfoundations, the authors are quite in the line of the new Keynesian assessment of the Lucas Critique, arguing, that the solution of more microfounded models with heterogeneous agents is not "always possible" (ibid.).

25 "I will run a pseudo-real-time exercise, looking at the policy advice that a policymaker from the 1970s would have derived from the estimation of the Smets-Wouters model, and comparing that to the performance of an old-style Phillips Curve estimated using ordinary least square (as a representation of a worst-case scenario for the technology available to this hypothetical policymaker)" (Hurtado, 2014, 15). 


\section{Conclusion}

This articles addressed the surprising disagreement within the "New Neoclassical Synthesis" about the vulnerability of DSGE models to the Lucas Critique. All the DSGE modelers involved in this debate claim that their contributions are not a pledge for abandoning DSGE models, but rather an encouragement to developing them: "We do not want our work to be interpreted as a sweeping criticism of the estimation of DSGE models, because it is not. [...] We ourselves have been engaged in this research agenda and plan to continue doing so." (Fernández-Villaverde and Rubio-Ramirez, 2007, 34); "Trying to perfect DSGE models [...] should be a top priority for the profession" (Hurtado, 2014, 20-21). However, when considered from our historical perspective, such good intentions are not likely to be a sufficient basis for actually solving the issue. Indeed, this article showed how the contemporary debate inherited from the rival interpretations of the methodological prescription presented in Lucas (1976). These divergent interpretations bring inevitably to two divergent solutions for building models for policy evaluation: on the one hand, those following the theoretical interpretation of the Critique put emphasis on developing "more" microfounded DSGE models; on the other side, microfoundations of DSGE models will not be enough for those endorsing the empirical interpretation of the Critique. DSGE models seem to be, for the moment, stuck in the middle of these conflicting methodological perspectives.

\section{References}

Argov, E., Barnea, E., Binyamini, A., Borenstein, E., Elkayam, D., and Rozenshtrom, I. (2012). MOISE: A DSGE model for the Israeli economy. Technical Report 2012.06, Bank of Israel.

Bernanke, B. S. (1983). The Determinants of Investment: Another Look. The American Economic Review, 73(2):71-75.

Black, F. (1982). General equilibrium and business cycles. Working Paper 950, National Bureau of Economic Research.

Blanchard, O. J. (1984). The Lucas Critique and the Volcker Deflation. The American Economic Review, 74(2):211-215.

Blinder, A. S. (1979). Economic Policy and the Great Stagflation. Academic Press, London. 
Braun, R. A. (1994). Tax Disturbances and Real Economic Activity in the Postwar United States. Journal of Monetary Economics, 33(3):441-462.

Calvo, G. A. (1983). Staggered prices in a utility-maximizing framework. Journal of monetary Economics, 12(3):383-398.

Caplin, A. S. and Spulber, D. F. (1987). Menu Costs and the Neutrality of Money. Quarterly Journal of Economics, 102(4):703-726.

Chang, Y., Kim, S.-B., and Schorfheide, F. (2010). Labor-market Heterogeneity, Aggregation, and the Lucas Critique. Technical Report 16401, National Bureau of Economic Research.

Chari, V. V., Christiano, L. J., and Kehoe, P. J. (1995). Policy analysis in business cycle models. In Cooley, T. F., editor, Frontiers of Business Cycle Research, pages 357-391. Princeton University Press New Jersey.

Chari, V. V., Kehoe, P. J., and McGrattan, E. R. (2008). New Keynesian Models: Not Yet Useful for Policy Analysis. Technical Report 14313, National Bureau of Economic Research.

Christiano, L. J. and Eichenbaum, M. (1992). Current Real-Business-Cycle Theories and Aggregate Labor-Market Fluctuations. The American Economic Review, 82(3):430-450.

Christiano, L. J., Eichenbaum, M., and Evans, C. L. (2005). Nominal Rigidities and the Dynamic Effects of a Shock to Monetary Policy. Journal of Political Economy, 113(1):1-45.

Cogley, T. and Yagihashi, T. (2010). Are DSGE Approximating Models Invariant to Shifts in Policy? The BE Journal of Macroeconomics, 10(1):131.

Cooley, T. F. and Hansen, G. D. (1989). The Inflation Tax in a Real Business Cycle Model. The American Economic Review, 79(4):733-748.

Cuche-Curti, N. A., Dellas, H., and Natal, J.-M. (2009). DSGE-CH: A dynamic stochastic general equilibrium model for Switzerland. Technical Report 5, Swiss National Bank.

Danthine, J.-P. and Donaldson, J. B. (1993). Methodological and empirical issues in real business cycle theory. European economic review, 37(1):1-35. 
De Vroey, M. (2011). Lucas on the relationship between theory and ideology. Economics: The Open-Access, Open-Assessment E-Journal, 5(2011-4):139.

De Vroey, M. (2015). A History of Modern Macroeconomics from Keynes to Lucas and Beyond. Cambridge University Press, Cambridge (UK).

Englander, A. S. and Los, C. A. (1983). The Stability of the Phillips Curve and its Implications for the 1980s. Federal Reserve Bank of New York, New York (NJ).

Engle, R. F., Hendry, D. F., and Richard, J.-F. (1983). Exogeneity. Econometrica, 51(2):277-304.

Ericsson, N. R. and Irons, J. S. (1995). The Lucas Critique in Practice: Theory without Measurement. International Finance Discussion Papers 506, Board of the Governors of the Federal Reserve System.

Estrella, A. and Fuhrer, J. C. (2003). Monetary Policy Shifts and the Stability of Monetary Policy Models. Review of Economics and Statistics, 85(1):94104.

Fernández-Villaverde, J. and Rubio-Ramirez, J. (2007). How Structural Are Structural Parameters? Technical Report 13166, National Bureau of Economic Research.

Frisch, R. (1938). Autonomy of Economic Relations. Statistical versus Theoretical Relations in Economic Macrodynamics. in Hendry, D. F. and Morgan, M.S. (1995). The Foundations of Econometric Analysis, Cambridge University Press, Cambridge (UK).

Gordon, R. J. (1990). What Is New-Keynesian Economics? Journal of Economic Literature, 28(3):1115-1171.

Goutsmedt, A., Pinzon-Fuchs, E., Renault, M., and Sergi, F. (2015). Criticizing the Lucas Critique: Macroeconometricians' Response to Robert Lucas. Documents de travail du CES 2015.59, Centre d'Economie de la Sorbonne (CES).

Goutsmedt, A., Pinzon-Fuchs, E., Renault, M., and Sergi, F. (2017). Reacting to the Lucas Critique. Some Keynesian Pragmatic Replies. Communication at the conference "The History of Macroeconometric Modelling", Utrecht, 6-7 April 2017. 
Greenwood, J. and Huffman, G. W. (1991). Tax analysis in a real-businesscycle model: On measuring harberger triangles and okun gaps. Journal of Monetary Economics, 27(2):167 - 190.

Haavelmo, T. (1944). The Probability Approach in Econometrics. Econometrica, 12(Supplement):iii-vi+1-115.

Hall, R. E. (1996). Robert Lucas, Recipient of the 1995 Nobel Memorial Prize in Economics. The Scandinavian Journal of Economics, 98(1):33-48.

Hansen, L. P. and Sargent, T. J. (1981). Formulating and Estimating Dynamic Linear Rational Expectations Models. In Lucas, R. E. and Sargent, T. J., editors, Rational Expectations and Econometric Practice, pages 91125. George Allen and Unwin Ltd., London. First published in the Journal of Economic Dynamics and Control in 1980.

Hendry, D. F. and Muellbauer, J. N. (2018). The Future of Macroeconomics: Macro Theory and Models at the Bank of England. Oxford Review of Economic Policy, 34(1-2):287-328.

Hoover, K. D. (2012). Microfoundational programs. In Duarte, P. G. and Lima, G. T., editors, Microfoundations Reconsidered, pages 19-61. Edward Elgar, Cheltenham (UK).

Hurtado, S. (2014). DSGE models and the Lucas critique. Economic Modelling, 44(Supplement 1):S12 - S19.

Ingram, B. and Leeper, E. (1990). Post Econometric Policy Evaluation: A Critique. Technical Report 393, Board of Governors of the Federal Reserve System.

Inoue, A. and Rossi, B. (2008). Which Structural Parameters Are "Structural"? Identifying the Sources of Instabilities in Economic Models. Technical Report 08-02, Economic Department, Duke University.

Ireland, P. N. (2004). A Method for Taking Models to the Data. Journal of Economic Dynamics and Control, 28(6):1205-1226.

Juselius, K. and Franchi, M. (2007). Taking a DSGE Model to the Data Meaningfully. Economics: The Open-Access, Open-Assessment E-Journal, 2007(4):1-38.

Klamer, A. (1984). The New Classical Macroeconomics. Conversations with the New Classical Economists and Opponents. Wheatsheaf Books, Brighton (UK). 
Klein, L. R. and Goldberger, A. S. (1955). An Econometric Model of the United States, 1929-1952. North Holland, Amsterdam.

Kydland, F. E. and Prescott, E. C. (1977). Rules Rather than Discretion: The Inconsistency of Optimal Plans. Journal of Political Economy, 85(3):473-491.

Kydland, F. E. and Prescott, E. C. (1982). Time to Build and Aggregate Fluctuations. Econometrica, 50(6):1345-1370.

Kydland, F. E. and Prescott, E. C. (1991). The Econometrics of the General Equilibrium Approach to Business Cycles. The Scandinavian Journal of Economics, 93(2):161-178.

Long, John B., J. and Plosser, C. I. (1983). Real Business Cycles. Journal of Political Economy, 91(1):39-69.

Lubik, T. A. and Surico, P. (2010). The Lucas Critique and the Stability of Empirical Models. Journal of Applied Econometrics, 25(1):177-194.

Lucas, R. E. (1976). Econometric Policy Evaluation: A Critique. CarnegieRochester Conference Series on Public Policy, 1:19-46.

Lucas, R. E. (1981). Studies in Business-Cycle Theory. MIT Press, Cambridge, MA.

Lucas, R. E. (1987). Models of Business Cycles. Basil Blackwell, Oxford.

Lucas, R. E. and Sargent, T. (1979). After Keynesian Macroeconomics. Federal Reserve of Minneapolis Quarterly Review, 3(2):49-82.

Lucas, R. E. and Sargent, T. J. (1981). Rational Expectations and Econometric Practice. George Allen and Unwin Ltd., London.

Mankiw, N. and Romer, D. (1991). Introduction. In Mankiw, N. and Romer, D., editors, New Keynesian Economics, MIT Press Readings in Economics, pages 1-26. MIT Press, Cambridge (MA).

Marschak, J. (1953). Economic Measurement for Policy and Prediction. In Hood, W. C. and Koopmans, T. G., editors, Studies in Econometric Method, pages 1-26. Wiley, New York. Cowles Commission Monograph, nr. 14.

McGrattan, E. R. (1994). The Macroeconomic Effects of Distortionary Taxation. Journal of Monetary Economics, 33(3):573-601. 
Miller, P. J. (1994). The Rational Expectations Revolution: Readings from the Front Line. MIT Press, Cambridge (MA).

Parkin, M. (1986). The Output-Inflation Trade-off When Prices Are Costly to Change. Journal of Political Economy, 94(1):200-224.

Plosser, C. I. (2012). Macro Models and Monetary Policy Analysis. In Bundesbank-Federal Reserve Bank of Philadelphia Research Conference. http://www.philadelphiafed.org/publications/speeches/ plosser/2012/05-25-12_bundesbank.pdf.

Qin, D. (2013). A History of Econometrics: The Reformation from the 1970s. Oxford University Press, Oxford.

Qin, D. (2014). Inextricability of Autonomy and Confluence in Econometrics. Economia. History, Methodology, Philosophy, 4(3):321-341.

Rudebusch, G. D. (2005). Assessing the Lucas Critique in Monetary Policy Models. Journal of Money, Credit and Banking, 37(2):245-272.

Sergi, F. (2015). Robert Lucas and the Twist of Modeling Methodology. On some Econometric Methods and Problems in New Classical Macroeconomics. Documents de travail du CES 2015.88, Centre d'Economie de la Sorbonne (CES).

Sergi, F. (2017a). De la révolution lucasienne aux modèles DSGE. Réflexions sur les développements récents de la modélisation macroéconomique. $\mathrm{PhD}$ thesis, Université Paris 1 Panthéon Sorbonne, Paris.

Sergi, F. (2017b). The Standard Narrative on History of Macroeconomics: Central Banks and DSGE Models. Communication at the Annual Meeting of the History of Economics Society, Toronto, 22/06/2017.

Sims, C. (1982). Policy Analysis with Econometric Models. Brookings Papers on Economic Activity, 1982(1):107-164.

Sims, C. A. (1980). Macroeconomics and Reality. Econometrica, 48(1):1-48.

Smets, F. and Wouters, R. (2005). Comparing shocks and frictions in US and euro area business cycles: A Bayesian DSGE approach. Journal of Applied Econometrics, 20(2):161-183.

Snowdon, B. (2007). The New Classical Counter-Revolution: False Path or Illuminating Complement? Eastern Economic Journal, 33(4):541-562. 
Snowdon, B. and Vane, H. R. (2005). Modern Macroeconomics: its Origins, Development and Current State. Edward Elgar, Cheltenham (UK).

Spanos, A. (2014). Reflections on the LSE Tradition in Econometrics: A Student's Perspective. Economia. History, Methodology, Philosophy, 3(4):343-380.

Taylor, J. B. (1984). Recent Changes in Macro Policy and its Effects: Some Time-Series Evidence. The American Economic Review, 74(2):206-210.

Taylor, J. B. (1993). Discretion versus policy rules in practice. CarnegieRochester Conference Series on Public Policy, 39(Décembre):195-214.

Tinbergen, J. (1956). Economic Policy: Principles and Design. North Holland, Amsterdam.

Woodford, M. (2003). Interest and Prices. Foundations of a Theory of Monetary Policy. Princeton University Press, Princeton. 
Recent UWE Economics Papers

See https://www1.uwe.ac.uk/bl/research/bcef/publications.aspx for a full list.

$\underline{2018}$

1806 DSGE Models and the Lucas Critique. A Historical Appraisal Francesco Sergi

1805 A new approach to estimating interregional output multipliers using inputoutput data for South Korean regions

Malte Jahn, Anthony T. Flegg and Timo Tohmo

1804 Urban food security in the context of inequality and dietary change: a study of school children in Accra

Sara Stevano, Deborah Johnston and Emmanuel Codjoe

1803 The use of differential weighting and discounting in degree algorithms and their impact on classification inflation and equity: A further analysis

David O. Allen

1802 Unambiguous inference in sign-restricted VAR models

Robert Calvert Jump

1801 Degree algorithms, grade inflation and equity: the UK higher education sector David O. Allen

$\underline{2017}$

1706 Internal rationality, heterogeneity and complexity in the new Keynesian model Cars Hommes, Robert Calvert Jump and Paul Levine

1705 The regionalization of national input-output tables: a study of South Korean regions Anthony T. Flegg and Timo Tohmo

1704 The impact of quantitative easing on aggregate mutual fund flows in the UK Iris Biefang-Frisancho Mariscal

1703 Where are the female CFOs?

Gail Webber, Don J Webber, Dominic Page and Tim Hinks

1702 Mental health and employment transitions: a slippery slope Don J Webber, Dominic Page and Michail Veliziotis

1701 SMEs access to formal finance in post-communist economies: do institutional structure and political connectedness matter?

Kobil Ruziev and Don J Webber 
1611 Curriculum reform in UK economics: a critique

Andrew Mearman, Sebastian Berger and Danielle Guizzo

1610 Can indeterminacy and self-fulfilling expectations help explain international business cycles?

Stephen McKnight and Laura Povoledo

1609 Pricing behaviour and the role of trade openness in the transmission of monetary shocks

Laura Povoledo

1608 Measuring compliance with minimum wages

Felix Ritchie, Michail Veliziotis, Hilary Drew and Damian Whittard

1607 Can a change in attitudes improve effective access to administrative data for research? Felix Ritchie

1606 Application of ethical concerns for the natural environment into business design: a novel business model framework

Peter Bradley, Glenn Parry and Nicholas O’Regan

1605 Refining the application of the FLQ Formula for estimating regional input coefficients: an empirical study for South Korean regions

Anthony T. Flegg and Timo Tohmo

1604 Higher education in Uzbekistan: reforms and the changing landscape since independence

Kobil Ruziev and Davron Rustamov

1603 Circular economy

Peter Bradley

1602 Do shadow banks create money? 'Financialisation' and the monetary circuit Jo Michell

1601 Five Safes: designing data access for research

Tanvi Desai, Felix Ritchie and Richard Welpton

1509 Debt cycles, instability and fiscal rules: a Godley-Minsky model Yannis Dafermos 
1508 Evaluating the FLQ and AFLQ formulae for estimating regional input coefficients: empirical evidence for the province of Córdoba, Argentina Anthony T. Flegg, Leonardo J. Mastronardi and Carlos A. Romero

1507 Effects of preferential trade agreements in the presence of zero trade flows: the cases of China and India

Rahul Sen, Sadhana Srivastava and Don J Webber 